\title{
Neuropsychiatric effects of caffeine
}

\section{Anthony P. Winston, Elizabeth Hardwick \& Neema Jaberi}

\begin{abstract}
Psychiatrists rarely enquire about caffeine intake when assessing patients. This may lead to a failure to identify caffeine-related problems and offer appropriate interventions. Excessive caffeine ingestion leads to symptoms that overlap with those of many psychiatric disorders. Caffeine is implicated in the exacerbation of anxiety and sleep disorders, and people with eating disorders often misuse it. It antagonises adenosine receptors, which may potentiate dopaminergic activity and exacerbate psychosis. In psychiatric in-patients, caffeine has been found to increase anxiety, hostility and psychotic symptoms. Assessment of caffeine intake should form part of routine psychiatric assessment and should be carried out before prescribing hypnotics. Gradual reduction in intake or gradual substitution with caffeine-free alternatives is probably preferable to abrupt cessation. Decaffeinated beverages should be provided on psychiatric wards.
\end{abstract}

'... coffee sets the blood in motion and stimulates the muscles; it accelerates the digestive processes, chases away sleep, and gives us the capacity to engage a little longer in the exercise of our intellects.'

Honoré de Balzac (paraphrasing Brillat-Savarin) Traité des Excitants Modernes (1838), (translated from the French by Robert Onopa)

Caffeine is the most widely used psychoactive drug in the world. It is found in more than 60 known species of plants, and dietary sources include coffee, tea, cocoa beverages, chocolate and soft drinks. Coffee was consumed in Arabia in the 13th century and was introduced into Europe in the early 17th century. Tea was probably drunk in China before the birth of Christ and was brought to Europe in the 16th century. Most dietary caffeine is still consumed as tea and coffee, and the latter accounts for $55 \%$ of per capita intake in the UK (Scott et al, 1989). Despite (or perhaps because of) its ubiquity, caffeine is rarely thought of as a problematic drug. Doctors do not often ask patients about its use and enquiry into caffeine consumption is not usually included in psychiatric assessment.

On average, a cup of brewed coffee contains $100 \mathrm{mg}$ of caffeine, compared with $75 \mathrm{mg}$ for instant coffee and $50 \mathrm{mg}$ for tea (Food Standards Agency, 2001); a can of Coca Cola contains $30 \mathrm{mg}$. Increasingly, stimulant drinks such as Red Bull ( $80 \mathrm{mg}$ of caffeine per can) are being marketed to the public, and sales have increased dramatically since they first became available in 1987 (Finnegan, 2003). Pharmaceutical caffeine may be bought over the counter (for example as ProPlus tablets) and is also contained in numerous proprietary analgesics, cold and 'flu remedies, diet pills and diuretics; Anadin Extra, for example, contains $90 \mathrm{mg}$ of caffeine per dose. In the $\mathrm{UK}$, mean caffeine consumption is estimated at $359 \mathrm{mg} /$ day (Scott et al, 1989).

\section{Effects and diagnostic classification}

The primary effect of caffeine is to relieve fatigue and enhance mental performance. Excessive ingestion leads to a state of intoxication known as caffeinism, which is characterised by restlessness, agitation, excitement, rambling thought and speech, and insomnia. These symptoms clearly overlap with those of many psychiatric disorders. The potential harmful effects of caffeine have long been recognised. As long ago as 1900, the Journal of the American Medical Association reported a conference on 'Coffee as a beverage: its deleterious effects on the nervous system', at which a contributor complained that 'most physicians had given the subject little if any attention'. Another contributor asserted that coffee could cause a variety of symptoms, including depression, irritability, insomnia, tremulousness, loss of appetite and 'frequent eructations of gas' (JAMA, 2001). 
Four caffeine-related syndromes are recognised in DSM-IV (American Psychiatric Association, 1994): caffeine intoxication; caffeine-induced anxiety disorder; caffeine-induced sleep disorder; and caffeine-related disorder not otherwise specified. Caffeine withdrawal is included in the Appendix to DSM-IV under 'Criteria sets and axes provided for further study'. The ICD-10 (World Health Organization, 1992) is less specific. It recognises 'Mental and behavioural disorders due to use of other stimulants, including caffeine' (F15), which are then sub-classified in the same way as other substance use disorders (acute intoxication, harmful use, dependence syndrome, withdrawal state, etc.). However, there is no specific guidance on diagnosing problems due to caffeine misuse, and the diagnostic criteria are the same as for other substance use disorders. The prevalence of the various caffeinerelated syndromes is uncertain.

Despite this formal recognition, caffeine generally receives little attention from psychiatrists. For example, the New Oxford Textbook of Psychiatry (Gelder et al, 2003) does not discuss caffeine misuse, although caffeine is mentioned briefly as a cause of insomnia. Consequently, psychiatrists rarely enquire about caffeine intake when assessing patients. This may lead to a failure to identify caffeine-related problems and offer appropriate interventions.

This article describes the clinical effects of caffeine consumption in a variety of psychiatric disorders and offers some guidance on assessing and managing caffeine-related problems.

\section{Biochemistry and pharmacology of caffeine}

Caffeine is a methylxanthine (1,3,7-trimethylxanthine). The effects of this group of chemicals include stimulation of the central nervous system (CNS), diuresis, stimulation of cardiac muscle and relaxation of smooth muscle. Caffeine initially stimulates the CNS at the level of the cerebral cortex and medulla and only later stimulates the spinal cord (at higher doses). Its effects begin within $1 \mathrm{~h}$ and last for 3-4 h (Baker \& Theologus, 1972). Caffeine is rapidly absorbed from the gastrointestinal tract and then metabolised by demethylation and oxidation in the liver. There is some individual variation in the rate of metabolism; the half-life is reduced in smokers but increased in pregnancy and in women taking oral contraceptives (Finnegan, 2003).

Biochemically, the main action of caffeine is anatagonism of adenosine $A_{1}$ and $A_{2}$ receptors. Higher doses cause inhibition of phosphodiesterases, blockade of $\gamma$-aminobutyric acid type $\mathrm{A}\left(\mathrm{GABA}_{\mathrm{A}}\right)$ receptors and release of intracellular calcium (Daly
\& Fredholm, 1998; Finnegan, 2003). Neuropsychiatric effects are mediated largely by blockade of $A_{1}$ and $A_{2 A}$ receptors in the CNS. Adenosine $A_{1}$ receptors are present in almost all brain areas, but particularly in the hippocampus, cerebral cortex, cerebellar cortex and thalamus.

There are important connections between adenosine receptors and the dopaminergic system, which may be relevant to the effects of caffeine in psychosis (see below, in the subsection 'Schizophrenia'). Adenosine $A_{2 A}$ receptors are concentrated in the dopamine-rich regions of the brain and are thought to have considerable links with dopaminergic receptors (Ferre et al, 1992; Lorist \& Tops, 2003). Moreover, there is evidence that the stimulatory effects of caffeine require intact dopaminergic neurotransmission (Ferre et al, 1992). These stimulatory effects appear to result primarily from blockade of $A_{2 A}$ receptors, which stimulate inhibitory GABAergic neurons in pathways to the dopaminergic reward system of the striatum (Daly \& Fredholm, 1998). Blockade of adenosine receptors also reverses the inhibition of adrenaline release in the sympathetic nervous system and results in sympathetic stimulation (Kruger, 1996).

Elsewhere in the body, caffeine causes relaxation of smooth muscle (especially bronchial smooth muscle) and stimulation of cardiac muscle; these effects resemble those of $\beta$-adrenoceptor stimulation. The stimulatory effect on the heart can result in tachycardia at high doses.

\section{Psychological effects}

The psychological effects of caffeine are biphasic. Low doses produce stimulation, which is often perceived as desirable, whereas high doses can cause the unpleasant effects of caffeinism (Daly \& Fredholm, 1998). Caffeine increases alertness, reduces fatigue and can elevate mood (Leinart \& Huber, 1966; Rogers \& Dernoncourt, 1997; Smith, 2002). Normal consumption improves performance on tasks that require alertness, such as simulated driving tasks (Smith, 2002). The effect on more complex cognitive tasks is less clear, although there is evidence to suggest that high consumption is associated with better performance, especially in older people (Smith, 2002).

\section{Adverse effects}

Caffeine has a number of adverse effects on the gastrointestinal tract. It relaxes the lower oesophageal sphincter and can predispose to gastro-oesophageal reflux disease. It also causes gastric hypersecretion, which is associated with susceptibility to ulceration. 
It increases the rate of gastric emptying and the acidic gastric contents therefore pass more rapidly into the duodenum; this can lead to inflammation of the duodenal mucosa (Boekema et al, 1999).

The diuretic action of caffeine is well known. The public is often advised to abstain from consuming caffeine in situations where dehydration may be significant, such as long-haul flights. A recent review (Maughan \& Griffin, 2003) concluded that single doses of caffeine such as those found in commonly consumed beverages have little or no diuretic action, although large doses (>250 mg) do.

Caffeine may precipitate sinus tachycardia but does not increase the risk of cardiac arrhythmias, except perhaps at very high dose (Katan \& Schouten, 2005). It can trigger migraine in susceptible individuals (Goadsby, 2003). Excessive use of caffeine-containing analgesics has been linked to analgesic nephropathy (De Broe et al, 2003). Caffeine may also be harmful in pregnancy; intakes above $300 \mathrm{mg} /$ day may be associated with low birth weight and miscarriage (Food Standards Agency, 2001; Parazzini et al, 2005). The UK Food Standards Agency has recommended that pregnant women should limit their intake to less than this amount, which is equivalent to four average-sized cups or three average-sized mugs of instant coffee or six average-sized cups of tea (Food Standards Agency, 2001).

\section{Dependence and withdrawal}

Caffeine acts as a reinforcing agent in both humans and animals (Griffiths \& Munford, 1995), although its effect is less powerful than that of stimulants such as cocaine and amphetamine (Daly \& Fredholm, 1998). The reinforcing effect is thought to be due to both pleasurable stimulatory effects and unpleasant withdrawal symptoms (Daly \& Fredholm, 1998). Caffeine differs from classical drugs of misuse in causing dopamine release in the prefrontal cortex rather than the nucleus accumbens, which is the principal area involved in reward and addiction (Nehlig, 1999).

Withdrawal symptoms have been reported in both humans and animals (Schuh \& Griffiths, 1997; Griffiths \& Woodson, 1998). Well-recognised symptoms include headache, irritability, sleeplessness, confusion, nausea, anxiety, restlessness and tremor, palpitations and raised blood pressure (Finnegan, 2003). They typically start slowly, are at their worst at 1-2 days, and recede within a few days. They are rapidly relieved by intake of caffeine, suggesting that they are genuine withdrawal symptoms. Tolerance has been reported to the effects of caffeine on the respiratory and cardiovascular systems, but there is little tolerance to its effect on sleep or mood (Daly \& Fredholm, 1998).

Data on the prevalence of withdrawal symptoms are inconsistent, with a range of $11 \%$ or less to $100 \%$ (Dews et al, 2002). One study found that $7.5 \%$ of the population may experience adverse effects following either caffeine consumption or withdrawal (Scott et $a l, 1989)$. In another study (Dews et al, 1999), 11\% of caffeine consumers reported withdrawal symptoms. Among regular caffeine users, only $0.9 \%$ of males and $5.5 \%$ of females reported withdrawal symptoms significant enough to interfere with normal activities. Withdrawal symptoms appear to be more common in teenagers: in one sample, $77.8 \%$ reported withdrawal symptoms and $41.7 \%$ tolerance (Bernstein et al, 2002).

Overall, clinically significant withdrawal symptoms seem to be relatively uncommon in the general population (Dews et al, 1999). It has been suggested that there is a definable caffeine dependence syndrome, on the basis that some adults meet the DSM-IV criteria for substance dependence (Strain et al, 1994). However, many studies of caffeine withdrawal have methodological limitations (Smith, 2002) and the status of caffeine as a drug of dependence remains controversial.

\section{Caffeine and psychiatric disorder}

Consumption of caffeine may be higher in psychiatric patients than in the population as a whole (Greden et al, 1978; Galliano, cited in Scott et al, 1989). Caffeine use has been linked with specific disorders such as anxiety disorders, sleep disorders and eating disorders, and there is a possible association with schizophrenia. Surprisingly, there are no published reports linking caffeine use with mania or hypomania.

\section{Anxiety disorders}

The resemblance between the symptoms of excessive caffeine ingestion and those of anxiety is obvious and they may both have a basis in overactivity of the sympathetic nervous system. It has been argued that the symptoms of caffeinism are indistinguishable from those of anxiety (Greden, 1974). However, caffeinism is normally associated with a daily intake of $1000-1500 \mathrm{mg}$, and the relevance of Greden's observation to lower doses is uncertain (Smith, 2002). There is a substantial literature documenting the anxiogenic effects of caffeine in both experimental and realistic situations (e.g. Chait, 1992; Brice \& Smith, 2002; Botella \& Parra, 2003). The stimulation of anxiety in response to caffeine may be due to increased levels of lactate in the brain (Tancer et al, 
1991, 1994). The role of adenosine in mediating caffeine-induced anxiety is supported by the finding that there is an association between different anxiety levels after caffeine administration and polymorphisms on the $\mathrm{A}_{2 \mathrm{~A}}$ receptor gene (Alsene et al, 2003).

Clinically, caffeine may be involved in the precipitation, exacerbation or maintenance of anxiety disorders (Kruger, 1996). Sensitivity to caffeine is increased in people with panic disorder and social phobia, and administration of caffeine can provoke panic attacks in these individuals (Charney et al, 1985; Tancer et al, 1991, 1994). There are clinical reports of anxiety symptoms improving on caffeine withdrawal or limitation (Greden, 1974; Bruce \& Lader, 1989), and people suffering panic attacks may benefit from a reduction in their intake (Charney et al, 1985).

\section{Sleep disorders}

It is well-known that caffeine produces insomnia. It reduces slow-wave sleep in the early part of the sleep cycle and can reduce rapid eye movement (REM) sleep later in the cycle (Nicholson \& Stone, 1980). Caffeine increases episodes of wakefulness (Brezinova et al, 1975), and high doses in the late evening can increase the time taken to fall asleep (Smith, 2002). In elderly people, the use of medication containing caffeine is associated with an increased risk of difficulty in falling asleep (Brown et al, 1995).

\section{Eating disorders}

Clinical experience suggests that people with eating disorders such as bulimia nervosa and anorexia nervosa often consume large quantities of drinks containing caffeine, in the belief that caffeine increases metabolic rate and suppresses appetite. In people with anorexia nervosa, who are already at high risk of cardiac arrhthymias, the stimulant effect of caffeine on the heart may be dangerous. Excessive caffeine ingestion may also contribute to osteoporosis, which has a high prevalence in anorexia nervosa (Deal, 1997).

Surprisingly, caffeine consumption in people with eating disorders has received little attention in the literature. There is only one published study, carried out in the USA, that focuses on caffeine intake in this population (Krahn et al, 1991). This study of individuals with anorexia nervosa, bulimia nervosa and eating disorder not otherwise specified found that $14.6 \%$ had a high caffeine intake (over $750 \mathrm{mg}$ / day), 39.2\% had a moderate intake (250-750 mg/ day) and $46.3 \%$ had a low intake (<250 mg/day). High and moderate intakes were associated with an increased frequency of binge eating, compared with low intake. Those in the high-intake group were also more likely to misuse laxatives and diet pills and have higher levels of anxiety. High and moderate intake were associated with high scores on the Michigan Alcohol Screening Test. We are currently conducting a study of caffeine use in British people with eating disorders.

\section{Schizophrenia}

It has already been noted that there are connections between adenosine $A_{2 A}$ receptors and the dopaminergic system in the brain. As adenosine inhibits dopaminergic neurotransmission, blockade of $\mathrm{A}_{2 \mathrm{~A}}$ receptors by caffeine may increase dopaminergic activity and exacerbate psychotic symptoms (Ferre et al, 1992). Clinically, the symptoms of caffeine intoxication can mimic those of psychosis (Kruger, 1996) or be confused with the side-effects of medication (Hughes et al, 1998). Cessation of caffeine causes fatigue and drowsiness, which can be confused with the side-effects of psychotropic drugs (Hughes et al, 1998).

There is also evidence that people with schizophrenia have higher than average intakes of caffeine, although the literature is inconsistent. There are a number of case reports of high caffeine intakeamong in-patients with schizophrenia (Benson \& David, 1986; Zaslove et al, 1991). Studies published in the 1970s give conflicting results, one finding that $71 \%$ of in-patients used more than $500 \mathrm{mg}$ of caffeineper day (Winstead, 1976) and the other that only 17\% used more than this amount (Furlong, 1975). A more recent study found that the mean daily caffeine intake of 26 in-patients was $503 \mathrm{mg}$, with $38 \%$ using more than $555 \mathrm{mg}$ (Mayo et al, 1993).

Several theories have been advanced as to why people with schizophrenia might havehigh intakes of caffeine (Hughes et al, 1998). These include using caffeine to relieve boredom and apathy and to offset the sedating effects of antipsychotic medication. Many psychotropic drugs produce a dry mouth, which might increase the intake of caffeinated drinks. About $80 \%$ of people with schizophrenia smoke (Lohr \& Flynn, 1992) and these individuals may use more caffeine to make up for the increased elimination of caffeine due to heavy smoking (Swanson et al, 1994).

There have been a number of case reports of delusions and hallucinations after large intakes of caffeine by people both with (Mikkelsen, 1978; Zaslove et al, 1991) and without psychosis (McManamy \& Schube, 1936; Rush et al, 1995). One study of 78 people with schizophrenia found that caffeine intake was correlated with positive symptoms but not with negative symptoms (Goff 
et al, 1992). Another, small study found only a slight correlation between caffeine intake and severity of psychosis (Hamera et al, 1995).

Three studies have attempted to determine the effect of caffeine on psychotic symptoms in inpatients by comparing the effect of caffeinated and decaffeinated beverages. All used the Brief Psychiatric Rating Scale (BPRS; self-reported) and the Nurses Observation Scale for Inpatient Evaluation (NOSIE; nurse rated). The first found that scores on the anxiety and hostility sub-scales of the BPRS and irritability scores on the NOSIE were higher when caffeine was being consumed (De Freitas \& Schwartz, 1979). The second found that scores for hostility, hallucinations and unusual thought content on the BPRS and for irritability and psychosis on the NOSIE were correlated with caffeine intake (Koczapski et al, 1989). However, these changes were small and statistically questionable. The third study found no relationship on either scale between caffeine intake and anxiety, depression or total scores (Mayo et al, 1993).

In an experimental study, caffeine was administered intravenously to 13 patients with schizophrenia who had been caffeine free for 6 weeks (Lucas et al, 1990). The dose used (10 mg/ kg of body weight) was the equivalent of drinking seven cups of brewed coffee in a row. Caffeine increased both the total score and the unusual thoughts sub-scale score on the BPRS. Conversely, caffeine decreased withdrawal/retardation. Interestingly, this large dose did not increase anxiety scores. The results of this study are consistent with those of the clinical studies described above, but they need to be interpreted with caution because of the large dose and the lack of a control group of people without schizophrenia (Hughes et al, 1998).

\section{Interaction with antipsychotics}

Caffeine has been shown to react in vitro with antipsychotics to form an insoluble precipitate (Hirsch, 1979), which could lead to decreased absorption (Kruger, 1996). Evidence also suggests that it may compete with clozapine for metabolism by the cytochrome P450 (CYP) 1A2 isoenzyme and could potentiate the side-effects of clozapine (OdomWhite \& de Leon, 1996). This has not been tested experimentally, although a published case report suggests that caffeine can increase clozapine levels sufficiently to produce clinically significant side-effects (Odom-White \& de Leon, 1996). The literature also includes a case report of an individual with schizophrenia who experienced an acute exacerbation of psychotic symptoms when clozapine was combined with caffeinated drinks (Vainer \& Chouinard, 1994).

\section{Substance misuse}

Caffeine appears to prime reward-relevant dopaminergic circuits implicated in cocaine misuse, and has been found to reinstate extinguished cocaine-taking behaviour in rats (Worley et al, 1994). It may also influence the intake or actions of alcohol and benzodiazepines (Daly \& Fredholm, 1998). There is evidence that patients who are addicted to other drugs use more caffeine than general psychiatric patients (Hays et al, 1998). Caffeine consumption is often found to be higher in smokers than in nonsmokers (Istvan \& Matarazzo, 1984; Scott et al, 1989). This may reflect the increased elimination of caffeine due to heavy smoking, as mentioned above, or a general need for stimulation. On the other hand, one small study found that caffeine use was lower in patients undergoing alcohol detoxification than in the general population (Pristach et al, 1983).

\section{Children}

Caffeine intake is lower in children than in adults, with a mean daily intake of 14-22 mg for children between 1 and 9 years of age in the USA (Knight et al, 2004). Intake is likely to be higher in older children and adolescents, with the majority coming from soft drinks (Valek et al, 2004). Excessive consumption of caffeine by children and adolescents has been identified as a cause of headache, which usually resolves on withdrawal (Hering-Hanit \& Gadoth, 2003). Caffeine is also associated with sleep disturbance, with shorter nocturnal sleep duration, increased wake time after sleep onset and increased daytime sleep (Pollak \& Bright, 2003). It is unclear whether caffeine plays a significant role in behavioural disturbance in children.

\section{Psychiatric in-patients}

Among adult psychiatric patients in the USA, a significant number have been found to use large amounts of caffeine (750 mg or more per day); such individuals have higher levels of both anxiety and depression than those who consume less (Greden et al, 1978). Stimulation of the sympathetic nervous system by caffeine puts the body in 'fight or flight' mode. In psychiatric in-patients, who can neither fight nor flee, sympathetic arousal will produce excitement and anxiety, which may result in behavioural disturbance (Kruger, 1996).

In a study of long-stay psychiatric in-patients, switching to decaffeinated coffee for 3 weeks led to an improvement in anxiety, irritability and hostility, which was reversed when caffeine was reintroduced; reintroduction of caffeine also caused 
an increase in psychotic features (De Freitas \& Schwartz, 1979).

In institutionalised adults with learning disability, caffeine challenge following a period of abstinence resulted in an increase in disturbed behaviour (Searle, 1994). It has been reported in a naturalistic study that higher doses of phenothiazines are prescribed to in-patients supplied with caffeinated coffee than to those given decaffeinated (Shisslak et al, 1985). However, a double-blind crossover study found no correlation between caffeine consumption and anxiety, depression or behaviour in long-stay patients with schizophrenia (Mayo et al, 1993). Caffeine may antagonise the effect of benzodiazepines such as lorazepam and diazepam (File et al, 1982; Roache \& Griffiths, 1987; Kaplan et al, 1990; Kruger, 1996); it has been suggested that patients may use caffeine to reverse the effects of sedatives, so creating a vicious cycle (De Freitas \& Schwartz, 1979).

\section{Assessment and treatment of caffeine-related problems}

In summary, although there is little evidence that caffeine produces clinically significant dependence, it may play a contributory role in a variety of psychiatric disorders. Assessment of caffeine intake should therefore form part of routine psychiatric assessment. This is particularly important in people with anxiety and sleep disorders, eating disorders and substance misuse. Assessment can easily be incorporated into the assessment of alcohol and drug use. In people who misuse drugs or have an eating disorder, it is appropriate to ask about use of overthe-counter products that contain caffeine. Intake should be quantified roughly in terms of the number of cups/mugs of tea or coffee and cans of carbonated drinks consumed in an average day. This can be converted into daily caffeine intake (Box 1). Intake

\section{Box 1 Caffeine content of drinks and choco-} late

- Average cup of instant coffee

- Average mug of instant coffee

- Average cup of brewed coffee

- Average cup of tea

- Regular can of cola drink

- Regular can of energy drink

- Plain $50 \mathrm{~g}$ bar of chocolate

- Milk 50 g bar of chocolate

$75 \mathrm{mg}$

$100 \mathrm{mg}$

$100 \mathrm{mg}$

$50 \mathrm{mg}$

up to $40 \mathrm{mg}$

up to $80 \mathrm{mg}$

up to $50 \mathrm{mg}$

up to $25 \mathrm{mg}$

(Data from Food Standards Agency, 2001, with permission)

\section{Box 2 Useful web addresses}

For the general public

http://www.eatwell.gov.uk/healthydiet/ nutritionessentials/drinks/waterandsoftdrinks

For professionals

Health effects:

http://www.jr2.ox.ac.uk/bandolier/band58/ b58-4.html

Psychiatric effects:

http://www.emedicine.com/med/topic3115. htm

may be classified as low ( $<250 \mathrm{mg} /$ day), moderate (250-750 mg/day) or high (>750 mg/day).

Psychiatrists should always enquire about use of caffeine before prescribing hypnotics. Other situations where caffeine intake may be relevant include poor response to hypnotics, recurrent headaches and palpitations (Greden, 1974). General practitioners, who see large numbers of patients with anxiety and sleep disorders, should also be made aware of the importance of caffeine and encouraged to ask about its use. Those who consume large amounts of caffeine should be given information about is effects and encouraged to reduce their intake.

If overuse of caffeine is established, gradual reduction in intake or gradual substitution with caffeine-free alternatives is probably preferable to abrupt cessation. Decaffeinated coffee and tea are now readily available. Although there have been concerns about potential carcinogenic effects when beverages are decaffeinated chemically, processes that use water and carbon dioxide seem to be safe. Caffeine-free cola is also becoming more available. Those responsible for in-patient psychiatric units should be aware of the potential role of excessive caffeine consumption in exacerbating sleep problems and behavioural disturbance and should encourage patients to reduce their consumption. Decaffeinated beverages should be provided on psychiatric wards.

Box 2 gives useful website addresses for further information on caffeine.

\section{References}

Alsene, K., Deckert, J., Sand, P., et al (2003) Association between A2a receptor gene polymorphisms and caffeine-induced anxiety. Neuropsychopharmacology, 28, 1694-1702.

American Psychiatric Association (1994) Diagnostic and Statistical Manual of Mental Disorders (4th edn) (DSM-IV). Washington, DC: APA.

Baker, W. \& Theologus, G. C. (1972) Effects of caffeine on visual monitoring. Journal of Applied Psychology, 56, 422427. 
Benson, J. I. \& David, J. J. (1986) Coffee eating in chronic schizophrenic patients. American Journal of Psychiatry, 143, 940-941.

Bernstein, G. A., Carroll, M. E., Thuras, P. D., et al (2002) Caffeine dependence in teenagers. Drug and Alcohol Dependence, 66, 1-6.

Boekema, P. J., Samson, M., van Berge Henegouwen, G. P., et al (1999) Coffee and gastrointestinal function: facts and fiction. A review. Scandinavian Journal of Gastroenterology Supplementum, 230, 35-39.

Botella, P. \& Parra, A. (2003) Coffee increases state anxiety in males but not in females. Human Psychopharmacology, 18(2), $141-143$.

Brezinova, V., Oswald, I. \& Loudon, J. (1975) Two types of insomnia: too much waking or not enough sleep. British Journal of Psychiatry, 126, 439-445.

Brice, C. F. \& Smith, A. P. (2002) Effects of caffeine on mood and performance: a study of realistic consumption. Psychopharmacology (Berlin), 164, 188-192.

Brown, S. L., Salive, M. E., Pahor, M., et al (1995) Occult caffeine as a source of sleep problems in an older population. Journal of the American Geriatrics Society, 43, 860-864.

Bruce, M. S. \& Lader, M. (1989) Caffeine abstention in the management of anxiety disorders. Psychological Medicine, 19, 211-214.

Chait, L. D. (1992) Factors influencing the subjective response to caffeine. Behavioural Pharmacology, 3, 219-228.

Charney, D. S., Heninger, G. R. \& Jatlow, P. I. (1985) Increased anxiogenic effects of caffeine in panic disorders. Archives of General Psychiatry, 42, 233-243.

Daly, J. W. \& Fredholm, B. B. (1998) Caffeine - an atypical drug of dependence. Drug and Alcohol Dependence, 51, 199 206.

Deal, C. L. (1997) Osteoporosis: prevention, diagnosis, and management. American Journal of Medicine, 102 (1A), 35S395.

De Broe, M. E., D’Haese, P. C. \& Elseviers, M. M. (2003) Chronic tubulointerstitial nephritis. In Oxford Textbook of Medicine (4th edn) (eds D. Warrell, T. M. Cox, J. D. Firth, et al), pp. 361-373. Oxford: Oxford University Press.

De Freitas, B. \& Schwartz, G. (1979) Effects of caffeine in chronic psychiatric patients. American Journal of Psychiatry, 136, 1337-1338.

Dews, P. B., Curtis, G. L., Hanford, K. J., et al (1999) The frequency of caffeine withdrawal in a population-based survey and in a controlled, blinded pilot experiment. Journal of Clinical Pharmacology, 39, 1221-1232.

Dews, P. B., O'Brien, C. P. \& Bergman, J. (2002) Caffeine: behavioral effects of withdrawal and related issues. Food and Chemical Toxicology, 40, 1257-1261.

Ferre, S., Fuxe, K., von Euler, G., et al (1992) Adenosinedopamine interactions in the brain. Neuroscience, 51, 501512.

File, S. E., Bond, A. J. \& Lister, R. G. (1982) Interaction between effects of caffeine and lorazepam in performance tests and self-ratings. Journal of Clinical Psychopharmacology, 2, 102106.

Finnegan, D. (2003) The health effects of stimulant drinks. Nutrition Bulletin, 28, 147-155.

Food Standards Agency (2001) Statement on the Reproductive Effects of Caffeine. London: Food Standards Agency.

Furlong, F. W. (1975) Possible psychiatric significance of excessive coffee consumption. Canadian Psychiatric Association Journal, 20, 577-583.

Gelder, M. G., Lopez-Ibor, J. J. \& Andreasen, N. C. (eds) (2003) New Oxford Textbook of Psychiatry. Oxford: Oxford University Press.

Goadsby, P. (2003) Headache: migraine, cluster headache, and other primary headaches. In Oxford Textbook of Medicine (4th edn) (eds D. Warrell, T. M. Cox, J. D. Firth, et al), pp. 993-1001. Oxford: Oxford University Press.

Goff, D. C., Henderson, D. C. \& Amico, E. (1992) Cigarette smoking in schizophrenia: relationship to psychopathology and medication side-effects. American Journal of Psychiatry, 149, 1189-1194.
Greden, J. F. (1974) Anxiety or caffeinism: a diagnostic dilemma. American Journal of Psychiatry, 131, 1089-1092.

Greden, J. F., Fontaine, P., Lubetsky, M., et al (1978) Anxiety and depression associated with caffeinism among psychiatric inpatients. American Journal of Psychiatry, 135 963-966.

Griffiths, R. R. \& Mumford, G. K. (1995) Caffeine - a drug of abuse? In Psychopharmacology: The Fourth Generation of Progress (eds F. E. Bloom \& D. J. Kupfer), pp. 1699-1713. New York: Raven Press.

Griffiths, R. R. \& Woodson, P. P. (1998) Reinforcing properties of caffeine: studies in humans and laboratory animals. Pharmacolooy, Biochemistry, and Behavior, 29, 419-427.

Hamera, E., Schneider, J. K. \& Deviney, S. (1995) Alcohol, cannabis, nicotine, and caffeine use and symptom distress in schizophrenia. Journal of Nervous and Mental Disease, $\mathbf{1 8 3}$ 559-565.

Hays, L. R., Farabee, D. \& Miller, W. (1998) Caffeine and nicotine use in an addicted population. Journal of Addictive Diseases, 17, 47-54.

Hering-Hanit, R. \& Gadoth, N. (2003) Caffeine-induced headache in children and adolescents. Cephalalgia, 23, 332335.

Hirsch, S. R. (1979) Precipitation of antipsychotic drugs in interaction with coffee or tea. Lancet, 2 (8152), 1130-1131.

Hughes, J. R., McHugh, P. \& Holtzman, S. (1998) Caffeine and schizophrenia. Psychiatric Services, 49, 1415-1417.

Istavan, J. \& Matarazzo, J. D. (1984) Tobacco, alcohol and caffeine use: a view of their interrelationships. Psychological Bulletin, 95, 301-326.

Journal of the American Medical Association (2001) JAMA 100 years ago. JAMA, 285, 384.

Kaplan, G. B., Tai, N. T., Greenblatt, D. J., et al (1990) Separate and combined effects of caffeine and alprazolam on motor activity and benzodiazepine receptor binding in vivo. Psychopharmacology (Berlin), 101, 539-544.

Katan, M. B. \& Schouten, E. (2005) Caffeine and arrhythmia American Journal of Clinical Nutrition, 81, 539-540.

Koczapski, A., Paredes, J., Kogan, C., et al (1989) Effects of caffeine on behavior of schizophrenic inpatients. Schizophrenia Bulletin, 15, 339-344.

Knight, C. A., Knight, I., Mitchell, D. C., et al (2004) Beverage caffeine intake in US consumers and subpopulations of interest: estimates from the Share of Intake Panel survey. Food and Chemical Toxicology, 42, 1923-1930.

Krahn, D. D., Hasse, S., Ray, A., et al (1991) Caffeine consumption in patients with eating disorders. Hospital and Community Psychiatry, 42, 313-315.

Kruger, A. (1996) Chronic psychiatric patients' use of caffeine: pharmacological effects and mechanisms. Psychological Reports, 78, 915-923.

Lienart, G. A. \& Huber, H. P. (1966) Differential effects of coffee on speed and power tests. Journal of Psychology: Interdisciplinary and Applied, 63, 269-274.

Lohr, J. B. \& Flynn, K. (1992) Smoking and schizophrenia. Schizophrenia Research, 8, 93-102.

Lorist, M. M. \& Tops, M. (2003) Caffeine, fatigue and cognition. Brain and Cognition, 53, 82-94.

Lucas, P. B., Pickar, D., Kelsoe, J., et al (1990) Effects of the acute administration of caffeine in patients with schizophrenia. Biological Psychiatry, 28, 35-40.

Maughan, R. J. \& Griffin, J. (2003) Caffeine ingestion and fluid balance: a review. Journal of Human Nutrition and Dietetics, 16, 411-420

Mayo, K. M., Falkowski, W. \& Jones, C. A. (1993) Caffeine: use and effects in long-stay psychiatric patients. British Journal of Psychiatry, 162, 543-545.

McManamy, M. C. \& Schube, P. G. (1936) Caffeine intoxication: report of a case the symptoms of which amounted to a psychosis. New England Journal of Medicine, 215, 616-620.

Mikkelsen, E. J. (1978) Caffeine and schizophrenia. Journal of Clinical Psychiatry, 39, 732-736.

Nehlig, A. (1999) Are we dependent upon coffee and caffeine? A review on human and animal data. Neuroscience and Biobehavioral Reviews, 23, 563-576. 
Nicholson, A. N. \& Stone, B. M. (1980) Heterocyclic amphetamine derivatives and caffeine on sleep in man British Journal of Clinical Pharmacology, 9, 195-203.

Odom-White, A. \& de Leon J (1996) Clozapine levels and caffeine. Journal of Clinical Psychiatry, 57, 175-176.

Parazzini, F., Chiaffarino, F., Chatenoud, L., et al (2005) Maternal coffee drinking in pregnancy and risk of small for gestational age birth. European Journal of Clinical Nutrition, 59, 299-301.

Pollak, C. P. \& Bright, D. (2003) Caffeine consumption and weekly sleep patterns in US seventh-, eighth-, and ninthgraders. Pediatrics, 111, 42-46.

Pristach, C. A., Smith, C. M. \& Whitney, R. B. (1983) Alcohol withdrawal syndromes - prediction from detailed medical and drinking histories. Drug and Alcohol Dependence, 11, 177-199.

Roache, J. D. \& Griffiths, R. R. (1987) Interactions of diazepam and caffeine: behavioral and subjective dose effects in humans. Pharmacology Biochemistry and Behavior, 26, 801812 .

Rogers, P. J. \& Dernoncourt, C. (1997) Regular caffeine consumption: a balance of adverse and beneficial effects for mood and psychomotor performance. Pharmacology, Biochemistry and Behavior, 59, 1039-1045.

Rush, C. R., Sullivan, J. T. \& Griffiths, R. R. (1995) Intravenous caffeine in stimulant drug abusers: subjective reports and physiological effects. Journal of Pharmacology and Experimental Therapeutics, 272, 351-358.

Schuh, K. J. \& Griffiths, R. R. (1997) Caffeine reinforcement: the role of withdrawal. Psychopharmacology, 130, 320326

Scott, N. R., Chakraborty, J. \& Marks, V. (1989) Caffeine consumption in the United Kingdom: a retrospective study. Food Sciences and Nutrition, 42F, 183-191.

Searle, G. F. (1994) The effect of dietary caffeine manipulation on blood caffeine, sleep and disturbed behaviour. Journal of Intellectual Disability Research, 38, 383-391.

Shisslak, C. M., Bleutler, L. E., Scheiber, S., et al (1985) Patterns of caffeine use and prescribed medications in psychiatric inpatients. Psychological Reports, 57, 39-42.

Smith, A. (2002) Effects of caffeine on human behavior. Food and Chemical Toxicology, 40, 1243-1255.

Strain, E. C., Mumford, G. K., Silverman, K., et al (1994) Caffeine dependence syndrome: evidence from case histories and experimental evaluations. JAMA, 272, 10431048.

Swanson, J. A., Lee, J. W. \& Hopp, J. W. (1994) Caffeine and nicotine: a review of their joint use and possible interactive effects in tobacco withdrawal. Addictive Behaviors, 19, 229 256

Tancer, M. E., Stein, M. B., \& Uhde, T. W. (1991) Lactate response to caffeine in panic disorder: a replication using an "anxious" control group. Biological Psychiatry, 29, 57A.

Tancer, M. E., Stein, M. B. \& Uhde, T. W. (1994) Lactic acid response to caffeine in panic disorder: comparison with social phobics and normal controls. Anxiety, 1, 138-140.

Vainer, J. L. \& Chouinard, G. (1994) Interaction between caffeine and clozapine. Journal of Clinical Psychopharmacology, 14, 284-285.

Valek, M., Laslavic, B. \& Laslavic, Z. (2004) Daily caffeine intake among Osijek High School students: questionnaire study. Croatian Medical Journal, 45, 72-75.

Winstead, D. K. (1976) Coffee consumption among psychiatric inpatients. American Journal of Psychiatry, 133 1447-1450.

World Health Organization (1992) The ICD-10 Classification of Mental and Behavioural Disorders - Clinical Descriptions and Diagnostic Guidelines. Geneva: WHO.

Worley, C. M., Valadez, A. \& Schenk, S. (1994) Reinstatement of extinguished cocaine-taking behavior by cocaine and caffeine. Pharmacology, Biochemistry, and Behavior, 48, 217221.

Zaslove, M. O., Russell, R. L. \& Ross, E. (1991) Effect of caffeine intake on psychotic in-patients. British Journal of Psychiatry, 159, 565-567.

\section{MCQs}

1 The effects of caffeine typically last for:

a $1-2 \mathrm{~h}$

b $3-4 h$

c $5-6 \mathrm{~h}$

d $7-8 \mathrm{~h}$

e $9-10 \mathrm{~h}$.

2 Stimulatory effects of caffeine appear to be due to blockade of:

a adenosine $A_{1}$ receptors

b $\beta$-adrenoceptors

c noradrenaline receptors

d dopaminergic receptors

e adenosine $\mathrm{A}_{2}$ receptors.

3 Caffeine has been shown to form an insoluble precipitate with:

a antidepressants

b benzodiazepines

c antipsychotics

d mood stabilisers

e pain killers.

4 Caffeinism is associated with doses of:

a $100-500 \mathrm{mg}$

b $\quad 500-1000 \mathrm{mg}$

c $\quad 1000-1500 \mathrm{mg}$

d $1500-2000 \mathrm{mg}$

e $\quad 2000-2500 \mathrm{mg}$.

5 Caffeine can potentiate the side-effects of:

a carbamazepine

b clozapine

c olanzapine

d chlorpromazine

e risperidone. 